\title{
Energy Consumption And Economic Growth In China: New Evidence From The Co-Integrated Panel VAR Model
}

Shuai Chen, University of Shanghai for Science and Technology, P. R. China

\begin{abstract}
This study is conducted to explore the relationship between energy consumption and economic growth in China over the period 1995-2010 using the panel time-series techniques under a multivariate framework. The results reveal that there are long-run co-integration relationship among variables real GDP, energy consumption, capital formation and labor force. Furthermore, based on the panel VEC model, there is bidirectional causality between economic growth and energy consumption, which is consistent with the growth hypothesis in terms of the energy consumption-growth nexus. The unidirectional causality from capital formation to energy consumption reveals that energy consumption cannot affect economic growth through capital formation. Additionally, real GDP, energy consumption, capital formation and labor force each respond to short-run deviations from long-run equilibrium with a slow adjustment speed. Finally, by estimating the panel VAR model, it is found that the responses of real GDP to a shock of energy consumption are negative, whereas the shock of real GDP changes is positive with most of the energy consumption response being absorbed during the six years. By variance decompositions derived from the orthogonalized impulse-response coefficient matrices, a shock in the energy consumption takes the biggest effect on real GDP in both short-run and long-run.
\end{abstract}

Keywords: Energy Consumption; Economic Growth; Panel VAR Model; Panel Granger Causality

\section{INTRODUCTION}

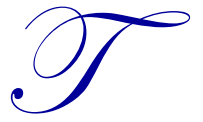

otally speaking, China is rich in natural resources with the energy, agriculture, forestry, and other commodity sectors providing much of the export-driven growth. The continued economic growth and large population also cause large demand for these resources. Many types of resource consumptions, like coal, petroleum et al., have been positioned among the world's leaders. The expansion of resource sectors has also contributed a lot to the high economic growth. What is followed is that China's economy is now heavily relying on large consumptions of natural resources especially the energy consumptions. The consumption growth rate of the main energy, including coal, petroleum, natural gas, hydro power and nuclear power, has surpassed their production growth rate over past years. Moreover, the energy gap between demand and supply begins to restrict growth for some regions. For example, China's east region's growth has been firstly slower than the middle and west since 2008. The annual GDP growth rate is $11.57 \%, 12.7 \%$ and $12.87 \%$ for the region of east, middle and west respectively. This trend has continued until 2011. The energy shortage for some regions becomes one major restricting factor for this phenomenon. It also shows that China's regional disparity in economic growth has been driven by the energy consumptions. Figure 1 describes energy consumption of all China over the period 1990-2010. In the paper, energy type includes coal, petroleum, natural gas, hydro power and nuclear power. It clearly indicates that the amount of energy consumption of China is increasing rapidly over the past 20 years. The growth rate of energy consumption has been increasingly high since 2002. Therefore, is there any causality relationship between energy consumption and economic growth? If it exists, is the causality unidirectional or bidirectional? To answer this question can help us clearly understand the role of energy consumption in China's growth, which is meaningful for improving China's energy polices and promoting long-run growth. 


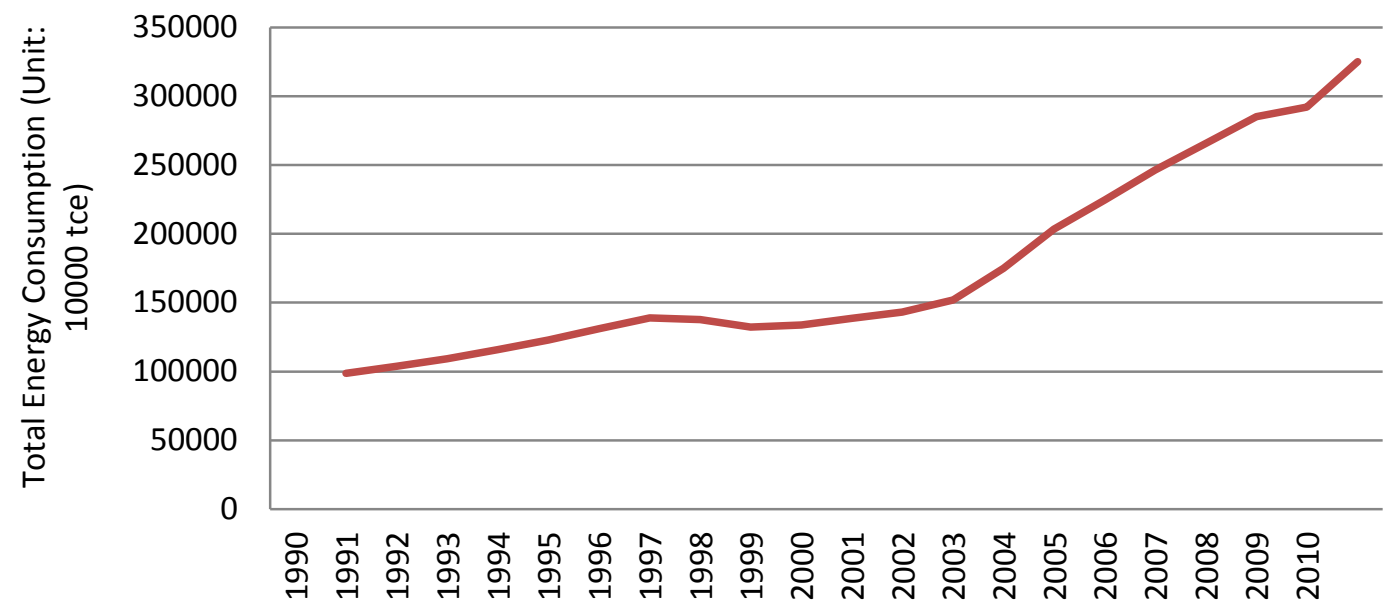

Figure 1: China's Total Energy Consumption (1990-2010)

Source: China Statistical Yearbook.

The object of this study is to examine the causality and dynamic relationship between energy consumption and economic growth for a panel of China's 30 provinces under a multivariate framework, in order to determine the degree to which energy consumption affects the growth prospects of China. Furthermore, from the Grangercausality test results, the paper aims to explore the dynamic responses of variables to different stochastic shocks within a multivariate economic system. Different from the simple time-series analysis, this paper employs panel time-series techniques to reflect the relationship comprehensively between energy consumption and economic growth. It combines the cross-section and time-series data, which allows for heterogeneity across provinces, thereof can improve the power and size properties of conventional unit root and co-integration tests.

This overview of China's situations of energy consumption and growth serve as points of references to examine the long-run and short-run relationship between energy consumption and economic growth. Section 2 reviews literatures associated with the theories and empirical studies on energy consumption and economic growth. Section 3 introduces the basic model, variables and datasets used for panel analysis in detail. Section 4 discusses econometric methodologies of the study, including panel unit root test, panel co-integration test, panel vector error correction (VEC) model, and panel vector autoregression (VAR) model. Following the common procedures of panel time-series analysis, it presents the empirical results and gives corresponding explanations. Finally, concluding remarks are given in Section 5.

\section{LITERATURE REVIEW}

The causality relationship between energy consumption and economic growth has been extensively examined in the literature with varying results across countries. The representative researches are completed by Apergis and Payne. They published three papers on the relationship between energy consumption and economic growth in 2009, 2010 and 2011 continuously. For the first two papers, under the same analytical framework, they mainly discuss the co-integration relationship and the Granger-causality in Central America and South America. It is found that both the long-run co-integration and the short-run Granger-causality between energy consumption and real GDP exist in the two regions, which is consistent with the growth hypothesis in terms of the energy consumption-growth nexus. For the third paper, they classify energy into renewable and non-renewable ones, and also find that in the 80 countries, both the co-integration and the Granger causality exist for the two types of energies. Using the similar methodologies in three papers, Apergis and Payne's empirical studies show that for different regions and energy types, the growth hypothesis always holds, which is based on the presence of the unidirectional causality from energy consumption to economic growth. In the case of 25 OECD countries, Belke, Dobnik and Dreger (2011) arrive at the similar conclusions that international developments dominate the long-run relationship between energy consumption and real GDP. Also, causality tests indicate the presence of bidirectional 
causality between energy consumption and growth. By classifications of developed and developing countries, Mahadevan and Adjave (2007) employ panel VEC model to obtain that among energy exporters there is bidirectional causality between economic growth and energy consumption in the developed countries in both shortrun and long-run, while in the developing countries energy consumption stimulates growth only in the short run. Compared to the developing countries, the developed countries' elasticity response is larger in terms of economic growth from an increase in energy consumption. The results show the different roles of energy consumption in growth for developed and developing countries, which does not support growth hypothesis any more. Under a multivariate framework, Yang and Yu (2011) examine causality between GDP and energy consumption using China's provincial panel data, and obtain that co-integration and Granger-causality is present. This paper does not give specific theories and empirical methods for estimations, and we cannot derive dynamic responses of variables under exogenous shocks. The study will be improved in these aspects. Apergis, Loomis and Payne (2010) examines whether or not U.S. natural gas consumption follows a stationary process. Unlike previous research that has focused on regional country or industrial sector-based panels, the study undertakes a sub-national investigation of natural gas consumption for the 50 U.S. states. It derives different conclusions of panel stationary tests using structural breaks, and also not included. This point can be served as references for the unit root tests.

However, the dynamic responses between energy consumption and economic growth are not given enough attention, and the panel vector autoregression (panel VAR) model has not been widely applied in the literatures yet, due to immature techniques of software. Love and Zicchino (2006) firstly make Stata codes of panel VAR, and apply to firm-level panel data from 36 countries to study the dynamic relationship between firms' financial conditions and investment by using orthogonalized impulse-response functions. After that, Mitze (2012) models the internal migration and regional market dynamics in Germany using panel VAR approach. It gives specific theoretical model and empirical analysis to predict the changes of German labor market under dynamic shocks. Therefore, these studies can provide us good references to make use of the panel VAR approach for the relationship research between energy consumption and economic growth. The review of relevant literatures can helps us understand the hypothesis of energy consumption-growth, and also provides references to improve the present econometric methods.

\section{MODEL AND DATA}

In order to explore the relationship between real GDP, energy consumption, capital formation, labor force and energy price for the panel of China's 30 provinces (mainland China provinces excluding Tibet), the production modeling framework is given as follows in general notion:

$$
Y_{i t}=f\left(E_{i t}, K_{i t}, L_{i t}, P_{i t}\right)
$$

To test panel unit root, causality and co-integration under the multivariate framework, the linear form of Eq. (1) is given by:

$$
\begin{aligned}
& Y_{i t}=\alpha_{0}+\alpha_{1 i} E_{i t}+\alpha_{2 i} K_{i t}+\alpha_{3 i} L_{i t}+\alpha_{4 i} P_{i t}+\varepsilon_{i t} \\
& \varepsilon_{i t}=\rho_{i} \varepsilon_{i t-1}+w_{i t}
\end{aligned}
$$

where all variables are in natural logarithms; $\mathrm{Y}_{\text {it }}$ denotes real GDP in 100 millions of constant $1978 \mathrm{RMB}$; $\mathrm{E}_{\mathrm{it}}$ is gross energy consumption in 10 thousands tce (tons of standard coal equivalent); $K_{i t}$ represents gross investment in fixed assets in 100 millions of $\mathrm{RMB}$; $\mathrm{L}_{\mathrm{it}}$ denotes gross number of staff and workers at the end of every year in 10 thousands; and $\mathrm{P}_{\mathrm{it}}$ is purchasing price indices of raw material, fuel and power in constant preceding year. Here, $\alpha_{1 \mathrm{i}}$, $\alpha_{2 \mathrm{i}}, \alpha_{3 \mathrm{i}}$, and $\alpha_{4 \mathrm{i}}$ represent the long-run elasticities of real GDP with respect to $\mathrm{E}_{\mathrm{it}}, \mathrm{K}_{\mathrm{it}}, \mathrm{L}_{\mathrm{it}}$, and $\mathrm{P}_{\mathrm{it}}$ separately.

Annual data from 1995 to 2010 were obtained from China Statistical Yearbook, China Compendium of Statistics and China Energy Statistical Yearbook for China's 30 provinces. Owing to data availability, Tibet is excluded from the samples. The data is compiled within a panel data framework in light of the relatively short time span of the data. The descriptive statistics, mean values, standard deviation and coefficient of variation of different variables for the panels are given below in Table 1. Here all the variables, which are in natural logarithms, are shown in Eq. (1). 
Table 1: Descriptive statistics

\begin{tabular}{clllll}
\hline Variable & Obs & Mean & Std. Dev. & Minimum & Maximum \\
\hline $\mathrm{Y}_{\text {it }}$ & 480 & 6.894 & 1.047 & 3.861 & 9.329 \\
$\mathrm{E}_{\mathrm{it}}$ & 480 & 8.625 & 0.829 & 5.714 & 10.600 \\
$\mathrm{~K}_{\mathrm{it}}$ & 480 & 7.313 & 1.168 & 4.018 & 10.055 \\
$\mathrm{~L}_{\text {it }}$ & 480 & 5.789 & 0.706 & 3.702 & 7.020 \\
$\mathrm{P}_{\mathrm{it}}$ & 480 & 4.650 & 0.065 & 4.445 & 4.802 \\
\hline
\end{tabular}

\section{ECONOMETRIC METHODOLOGY AND RESULTS}

Panel data analysis is a method of studying multiple phenomena observed over multiple time periods for the same individuals. It can reveal changes in laws and individual characteristics on the basis of the total information available for a sample. Following established procedures, we conduct the test of the dynamic causal relationship between economic growth, energy consumption, capital formation, labor force, and energy price. The testing procedure involves the following steps. At the first step, we test whether each variable contains a panel unit root. And if a unit root exists, a panel co-integration relationship among variables is tested to examine the long-run relationship. If a long-run relationship is found, we then estimate a panel vector error correction (VEC) model to infer the Granger causal relationship among variables, and examine the short-run relationship. Finally, we mainly focus on the dynamic relationship among variables. A panel VAR model is estimated using system GMM method, and then an orthogonalized impulse response functions is estimated to derive the impact of shocks among variables and the relative contributions by variance decompositions. In this paper, we adopt the software Stata and EViews for empirical analysis.

\subsection{Panel Unit Root Tests}

In order to infer the degree of integration and stationary properties of the respective variables for panel cointegration tests, a battery of panel unit root tests are performed, which have higher power than unit root tests based on individual time series suggested by recent literatures. Some newly developed panel unit root tests include Levin, Lin and Chu (LLC, 2002), Maddala and Wu (Fisher-ADF, 1999; Fisher-PP, 1999), Im, Pesaran and Shin (IPS, 2003), and Pesaran (CIPS, 2007).

Firstly, the panel based ADF test proposed by Levin et al. (2002) assumes homogeneity in the dynamics of the autoregressive coefficients for all panel units. Firstly, the following autoregressive model is given:

$$
y_{i t}=\rho_{i} y_{i t-1}+\delta_{i} X_{i t}+\varepsilon_{i t}
$$

where $i=1,2, \ldots, N$ represent provinces observed over periods $t=1,2, \ldots, T, X_{i t}$ are exogenous variables in the model including any fixed effects or individual trend, $\rho_{\mathrm{i}}$ are the autoregressive coefficients, and $\varepsilon_{\text {it }}$ is a stationary process. Here if $\rho_{\mathrm{i}}<1, \mathrm{y}_{\mathrm{i}}$ is said to be weakly trend-stationary. On the other hand, if $\rho_{\mathrm{i}}=1$, then $\mathrm{y}_{\mathrm{i}}$ contains a unit root.

Furthermore, Maddala and Wu (1999) employ nonparametric methods in conducting panel unit root tests using the Fisher-ADF test and Fisher-PP test which take advantage of allowing for as much heterogeneity across units as possible. They independently suggested a test against the heterogeneous alternative $\mathrm{H}_{1}$ that is based on the p-value of the individual specific unit root test applied to cross-section unit i. The test has a chi-square distribution with $2 \mathrm{~N}$ degrees of freedom, where $\mathrm{N}$ is the number of countries in the panel. The combined test statistic is given by

$$
\bar{\lambda}=-2 \sum_{i=1}^{N} \log _{e}\left(p_{i}\right) \sim \chi_{2 N(d . f .)}^{2}
$$

where $\mathrm{p}_{\mathrm{i}}$ is the $\mathrm{p}$-value from the ADF unit root tests for unit $\mathrm{i}$.

Another possibility would be to use the inverse normal test defined by 


$$
Z_{I N V}=\frac{1}{\sqrt{N}} \sum_{i=1}^{N} \Phi^{-1}\left(p_{i}\right)
$$

where $\Phi(\bullet)$ denotes the c.d.f. of the standard normal distribution. An important advantage of this approach is that it is possible to allow for different specifications (such as different deterministic terms and lag orders) for each panel unit. statistic

Under the null hypothesis is $\chi^{2}$ distributed with $2 \mathrm{~N}$ degrees of freedom. For large $\mathrm{N}$, the transformed

$$
\bar{\lambda}^{*}=-\frac{1}{\sqrt{N}} \sum_{i=1}^{N}\left[\log \left(p_{i}\right)+1\right]
$$

is shown to have a standard normal limiting null distribution as $\mathrm{T}, \mathrm{N} \rightarrow \infty$, sequentially.

Specifically, Im et al. (2003) averages the augmented Dickey-Fuller (ADF) unit root tests, while allowing for different orders of serial correlation:

$$
\varepsilon_{i t}=\sum_{j=1}^{p_{i}} \varphi_{i j} \varepsilon_{i t-j}+u_{i t}
$$

Substitution of Eq. (7) into Eq. (3) yields:

$$
y_{i t}=\rho_{i} y_{i t-1}+\sum_{j=1}^{p_{i}} \varphi_{i j} \varepsilon_{i t-j}+\delta_{i} X_{i t}+u_{i t}
$$

where $\rho_{\mathrm{i}}$ represents the number of lags in the ADF regression. The null hypothesis is that each series in the panel contains a unit root $\left(\mathrm{H}_{0}: \rho_{\mathrm{i}}=1\right)$. The alternative hypothesis is that at least one of the individual series in the panel is stationary $\left(\mathrm{H}_{1}: \rho_{\mathrm{i}}<1\right)$. Im et al. (2003) specify a t-bar statistic as the average of the individual ADF statistics as follows:

$$
\bar{t}=\frac{1}{N} \sum_{i=1}^{N} t_{\rho_{i}}
$$

where $\mathrm{t}_{\mathrm{i}}$ is the individual t-statistic for testing $\mathrm{H}_{0}: \rho_{\mathrm{i}}=1$ from Eq. (8). The t-bar statistic has been shown to be normally distributed under the null hypothesis $\mathrm{H}_{0}$, and the critical values for given values of $\mathrm{N}$ and $\mathrm{T}$ are provided in Im et al. (2003).

In addition, Pesaran (2007) proposed the CIPS test, based on a single common factor specification for the cross-correlation structure. It considers the dynamic linear heterogeneous panel data model:

$$
y_{i t}=\rho_{i} y_{i t-1}+\left(1-\rho_{i}\right) X_{i t}+\varepsilon_{i t}
$$

where $\varepsilon_{\text {it }}$ has the one common factor structure

$$
\varepsilon_{i t}=\gamma_{i} f_{t}+u_{i t}
$$

in which $\mathrm{f}_{\mathrm{t}} \sim$ i.i.d. $\left(0, \sigma_{\mathrm{f}}{ }^{2}\right)$ is the unobserved common effect, $\gamma_{\mathrm{i}} \sim$ i.i.d. $\left(0, \sigma_{\gamma}{ }^{2}\right)$ the individual factor loading, and $\mathrm{e}_{\mathrm{it}}$ the idiosyncratic component which can be i.i.d. $\left(0, \sigma_{\mathrm{i}}{ }^{2}\right)$, or more generally, a stationary autoregressive process. Rewriting (10) and (11) as

$$
\Delta y_{i t}=\alpha_{i}+\beta_{i} y_{i, t-1}+u_{i t}
$$


Pesaran proposed to proxy the common factor $f_{t}$ with the cross section mean of $y_{i t}$, namely $\bar{y}_{t}=N^{-1} \sum_{i=1}^{N} y_{i t}$ and its lagged values $\bar{y}_{t-1}, \bar{y}_{t-2}, \ldots$ The test for the null of unit root regarding the unit i can now be based on the $t$ ratio of the OLS estimate of $b_{i}$ in the cross-sectionally augmented Dickey-Fuller (CADF) regression

$$
\Delta y_{i t}=a_{i}+b_{i} y_{i, t-1}+c_{i} \bar{y}_{t-1}+d_{i} \Delta \bar{y}_{t}+u_{i t}
$$

A natural test of the null hypothesis $\mathrm{H}_{0}$ : $\beta_{\mathrm{i}}=0$ for all $\mathrm{i}$, against the heterogeneous alternative hypothesis $\mathrm{H}_{1}$ : $\beta_{1}<0, \ldots, \beta_{\mathrm{N} 0}<0, \mathrm{~N}_{0} \leq \mathrm{N}$ in the whole panel data set, is given by the average of the individual CADF statistics:

$$
\operatorname{CIPS}(N, T)=N^{-1} \sum_{i=1}^{N} t_{i}(N, T)
$$

The distribution of this test is non-standard, even asymptotically; $1 \%, 5 \%$ and $10 \%$ critical values are tabulated by the author for different combinations of $\mathrm{N}$ and $\mathrm{T}$.

Results of five types of panel unit root tests, as shown in Table 2, reveal that variables Y, E, K and L have unit roots, and are all integrated of order one, and variable $\mathrm{P}$ does not have unit root.

\begin{tabular}{|c|c|c|c|c|c|c|c|c|c|c|}
\hline Variables & LLC test & Prob. & Fisher-ADF test & Prob. & Fisher-PP test & Prob. & IPS test & Prob. & CIPS test & Prob. \\
\hline \multicolumn{11}{|c|}{ Level equations with only constant terms } \\
\hline $\mathrm{Y}$ & -0.084 & 0.145 & 0.587 & 1.000 & 0.751 & 1.000 & 1.172 & 0.879 & 1.920 & 0.973 \\
\hline $\mathrm{E}$ & $-0.135^{*}$ & 0.067 & 0.443 & 1.000 & 0.256 & 1.000 & 0.705 & 0.759 & $-3.650^{* * * *}$ & 0.000 \\
\hline $\mathrm{K}$ & $-2.180^{* *}$ & 0.015 & 1.632 & 1.000 & 0.551 & 1.000 & 0.581 & 0.720 & $-2.393^{* * * *}$ & 0.008 \\
\hline $\mathrm{L}$ & -0.122 & 0.430 & $174.156^{* * *}$ & 0.000 & $98.767^{* * *}$ & 0.001 & 0.339 & 0.633 & 2.336 & 0.990 \\
\hline $\mathrm{P}$ & $-1.068^{* * * *}$ & 0.000 & $134.213^{* * *}$ & 0.000 & $344.026^{* * * *}$ & 0.000 & $-8.390^{* * * *}$ & 0.000 & $-5.299^{* * *}$ & 0.000 \\
\hline \multicolumn{11}{|c|}{ Level equations with constant and trend terms } \\
\hline $\mathrm{Y}$ & -0.309 & 0.448 & 27.448 & 1.000 & 10.993 & 1.000 & 3.502 & 1.000 & 0.451 & 0.674 \\
\hline E & $-0.488^{* * * *}$ & 0.000 & 26.378 & 1.000 & 15.689 & 1.000 & -0.031 & 0.488 & $-4.479^{* * *}$ & 0.000 \\
\hline $\mathrm{K}$ & $-5.197^{* * * *}$ & 0.000 & 42.882 & 0.954 & 18.819 & 1.000 & 0.977 & 0.836 & $-2.350^{* * * *}$ & 0.009 \\
\hline $\mathrm{L}$ & -0.308 & 1.000 & 18.009 & 1.000 & $74.867^{*}$ & 0.094 & 2.206 & 0.986 & $-2.151^{* * *}$ & 0.016 \\
\hline $\mathrm{P}$ & $-1.267^{* * * *}$ & 0.000 & $147.060^{* * *}$ & 0.000 & $294.389^{* * * * *}$ & 0.000 & $-6.022^{* * * *}$ & 0.000 & $-2.886^{* * * *}$ & 0.002 \\
\hline \multicolumn{11}{|c|}{ First difference equations with constant and trend terms } \\
\hline$\Delta \mathrm{Y}$ & $-0.864^{* * *}$ & 0.000 & $136.805^{* * *}$ & 0.000 & $146.718^{* * * *}$ & 0.000 & $-1.382^{*}$ & 0.083 & 0.416 & 0.661 \\
\hline$\Delta \mathrm{E}$ & $-1.134^{* * * *}$ & 0.000 & $96.514^{* * *}$ & 0.002 & $100.107^{\text {*** }}$ & 0.001 & $-3.889^{* * * *}$ & 0.000 & $-5.163^{* * *}$ & 0.000 \\
\hline$\Delta \mathrm{K}$ & $-5.563^{* * *}$ & 0.000 & $143.434^{* * *}$ & 0.000 & $136.483^{* * *}$ & 0.000 & $-1.976^{* * *}$ & 0.024 & -1.014 & 0.155 \\
\hline$\Delta \mathrm{L}$ & -1.195 & 0.952 & $865.070^{* * *}$ & 0.000 & $386.592^{* * *}$ & 0.000 & $-7.837^{\text {**** }}$ & 0.000 & -1.204 & 0.114 \\
\hline$\Delta \mathrm{P}$ & $-1.888^{* * * *}$ & 0.000 & $180.181^{* * *}$ & 0.000 & $562.763^{* * * *}$ & 0.000 & $-8.697^{* * *}$ & 0.000 & $-3.672^{* * * *}$ & 0.000 \\
\hline
\end{tabular}

Table 2: Panel unit root tests

${ }_{* * *}^{* * *}$ denotes significance at the $1 \%$ level.

${ }^{* *}$ denotes significance at the $5 \%$ level.

${ }^{*}$ denotes significance at the $10 \%$ level.

\subsection{Panel Co-integration Tests}

It is established from the unit root tests that the variables except for $\mathrm{P}$ are all integrated of order one. Since co-integration test is applied into the integrated variables of the same orders, by taking no account of variable P, the next step is to employ co-integration analysis to determine whether a long-run relationship exists among other variables. Pedroni (1999 and 2004) proposes heterogeneous panel co-integration test, which allows for cross sectional interdependence with different individual effects, is estimated to determine whether a long-run equilibrium relationship exists as follows:

$$
Y_{i t}=\alpha_{i t}+\delta_{i} t+\alpha_{1 i} E_{i t}+\alpha_{2 i} K_{i t}+\alpha_{3 i} L_{i t}+\varepsilon_{i t}
$$


where $\mathrm{i}=1,2, \ldots, \mathrm{N}$ for each provinces in the panel, and $\mathrm{t}=1,2, \ldots, \mathrm{T}$ refers to the time period. Parameters $\alpha_{\mathrm{it}}$ and $\delta_{\mathrm{i}}$ allow for the possibility of province-specific fixed effects and deterministic trends separately. Deviations from the long-run equilibrium relationship are represented by the estimated residuals $\varepsilon_{\mathrm{it}}$.

The null hypothesis of no co-integration, $\rho_{\mathrm{i}}=1$, is tested via the following unit root test on the residuals:

$\varepsilon_{i t}=\rho_{i} \varepsilon_{i t-1}+w_{i t}$

Following Pedroni (1999 and 2004), two sets of panel co-integration tests are undertaken. Firstly, the panel tests, based on the within dimension approach, include four statistics: panel v, panel $\rho$, panel ADF, and panel PP statistics. These statistics essentially pool the autoregressive coefficients across different provinces for the unit root tests on the estimated residuals. These statistics take into account common time factors and heterogeneity across provinces. Secondly, the group tests are based on the between dimension approach which includes three statistics: group $\rho$, group ADF, and group PP statistics. These statistics are based on averages of the individual autoregressive coefficients associated with the unit root tests of the residuals for each province in the panel. All seven tests are distributed asymptotically as standard normal.

Because variables $\mathrm{Y}, \mathrm{E}, \mathrm{K}$ and $\mathrm{L}$ are all integrated of order one, and variable $\mathrm{P}$ does not have unit root, we will conduct co-integration test among variables $\mathrm{Y}, \mathrm{E}, \mathrm{K}$ and $\mathrm{L}$. Both panel co-integration test statistics of the within and the between dimension are reported in Table 3. Five test results reject the null hypothesis of no co-integration at the 1\% significance level. Panel ADF test reject the null hypothesis at the 5\% significance level. But panel PP test can not reject the null hypothesis. Therefore, we can conclude that there is long-run co-integration relationship among these variables.

Table 3: Panel co-integration tests

\begin{tabular}{|c|c|c|c|c|c|}
\hline Panel test statistics & & Prob. & $\begin{array}{c}\text { Group mean panel } \\
\text { statistics }\end{array}$ & & Prob. \\
\hline Panel v-statistic & $28.994^{* * * *}$ & 0.000 & Group $\rho$-statistic & $5.688^{* * * *}$ & 0.000 \\
\hline Panel $\rho$-statistic & $3.813^{* * *}$ & 0.000 & Group ADF-statistic & $-6.263^{* * *}$ & 0.000 \\
\hline Panel ADF-statistic & $-2.436^{* *}$ & 0.021 & Group PP-statistic & $-5.944^{* * *}$ & 0.000 \\
\hline Panel PP-statistic & -0.586 & 0.336 & & & \\
\hline
\end{tabular}

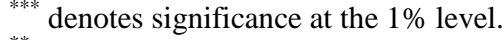

** denotes significance at the $5 \%$ level.

* denotes significance at the $10 \%$ level.

\subsection{Panel VEC Model}

\subsubsection{Estimation of Panel VEC Model}

Following Pesaran et al. (1999), the Engle and Granger (1987) two-step procedure is undertaken by firstly estimating the panel VEC model to derive the short-run relationship among variables. At the second step, based on the short-run estimation results, the joint F-test of coefficient is conducted to derive the Granger causality relationship. In the study, the two-step procedure is employed by firstly estimating the long-run model specified in

Eq. (15) to generate the estimated residuals ( $\hat{\varepsilon}_{i t}$ ), whose lagged values serve as the error correction term (ECM) in the estimation of the dynamic error correction model, of which the derivation forms are shown as follows:

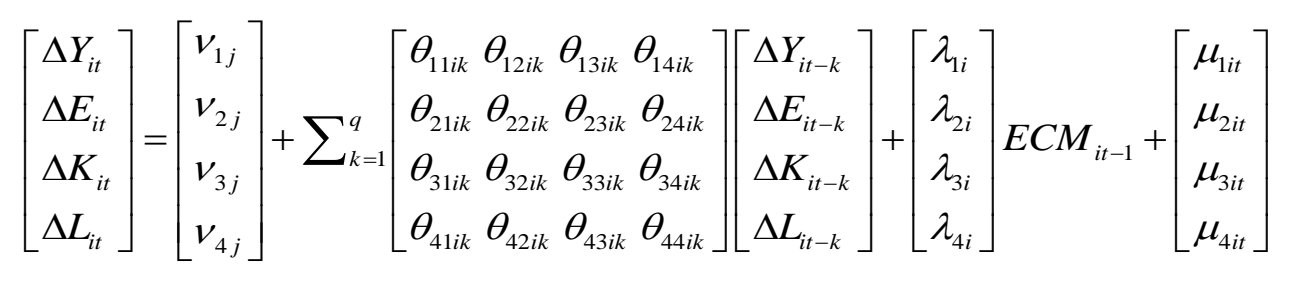




$$
E C M_{i t}=\left[\begin{array}{l}
\hat{\varepsilon}_{1 i t-1} \\
\hat{\varepsilon}_{2 i t-1} \\
\hat{\varepsilon}_{3 i t-1} \\
\hat{\varepsilon}_{4 i t-1}
\end{array}\right]
$$

where $\mathrm{i}=1,2, \ldots \ldots, \mathrm{n} ; \mathrm{t}=\mathrm{q}+1, \mathrm{q}+2, \mathrm{q}+3, \ldots \ldots . \mathrm{T}$; The $v$ 's, $\theta$ 's and $\lambda$ 's are the parameters to be estimated; $\Delta$ is the firstdifference operator; $\mathrm{k}$ is the lag length based on likelihood ratio tests; $\mathrm{ECM}_{\mathrm{it}-1}$ represents the one period lagged errorterm derived from the co-integration vector; and $\mu$ is the serially uncorrelated error term.

We estimate Eq. (17) using the pooled mean group regression. Maximum likelihood estimation is conducted to derive valid estimators, and the time length (value k) is determined by the likelihood ratio tests. Table 4 displays the results from the panel error correction model. Short-run term elasticity is determined by the statistical significance of the corresponding right-hand side variables in each equation using a Z-test. Long-run term elasticity is determined by the statistical significance of the respective error correction term (ECM) also using a Z-test. According to the results of Table 4, we can easily write Model (17) in the matrix form shown as Eq. (19).

Table 4: Short-run and long-run elasticities of panel VEC model

\begin{tabular}{|c|c|c|c|c|c|c|c|c|c|c|}
\hline \multirow{3}{*}{$\begin{array}{c}\text { Dependent } \\
\text { variable }\end{array}$} & \multicolumn{10}{|c|}{ Sources of causation (independent variable) } \\
\hline & \multicolumn{2}{|c|}{ Short-run } & \multirow[b]{2}{*}{$\Delta \mathrm{E}$} & \multirow[b]{2}{*}{ Prob. } & \multirow[b]{2}{*}{$\Delta \mathrm{K}$} & \multirow[b]{2}{*}{ Prob. } & \multirow[b]{2}{*}{$\Delta \mathrm{L}$} & \multicolumn{3}{|c|}{ Long-run } \\
\hline & $\Delta \mathrm{Y}$ & Prob. & & & & & & Prob. & ECM & Prob. \\
\hline (4a) $\Delta Y$ & - & - & -0.019 & 0.280 & $0.036^{*}$ & 0.063 & $0.061^{* * * *}$ & 0.001 & $-1.142^{* * * *}$ & 0.000 \\
\hline (4b) $\Delta \mathrm{E}$ & $1.562^{* * *}$ & 0.000 & - & - & -0.096 & 0.451 & 0.067 & 0.667 & $-0.517^{* * *}$ & 0.000 \\
\hline$(4 c) \Delta K$ & $1.895^{* * *}$ & 0.000 & 0.002 & 0.973 & - & - & 0.050 & 0.541 & $-0.172^{* * *}$ & 0.000 \\
\hline (4d) $\Delta \mathrm{L}$ & 0.142 & 0.689 & $-0.186^{* * * *}$ & 0.007 & $-0.119^{* *}$ & 0.014 & - & - & $-0.142^{* * *}$ & 0.000 \\
\hline
\end{tabular}

Notes: The summation of the lagged coefficients represents the respective short-run changes. ECM represents the coefficient of the error correction term, which is the long-run change. Probability values are reported besides every coefficient respectively. ${ }^{* *}$ denotes significance at the $1 \%$ level. ${ }^{* *}$ denotes significance at the $5 \%$ level. ${ }^{*}$ denotes significance at the $10 \%$ level.

$$
\left[\begin{array}{l}
\Delta Y_{i t} \\
\Delta E_{i t} \\
\Delta K_{i t} \\
\Delta L_{i t}
\end{array}\right]=\left[\begin{array}{c}
0.305 \\
1.076 \\
-0.616 \\
-0.507
\end{array}\right]+\sum_{k=1}^{q}\left[\begin{array}{cccc}
1 & -0.019 & 0.036 & 0.061 \\
1.562 & 1 & -0.096 & 0.067 \\
1.895 & 0.002 & 1 & 0.050 \\
0.142 & -0.186 & -0.119 & 1
\end{array}\right]\left[\begin{array}{l}
\Delta Y_{i t-k} \\
\Delta E_{i t-k} \\
\Delta K_{i t-k} \\
\Delta L_{i t-k}
\end{array}\right]+\left[\begin{array}{l}
-1.142 \\
-0.517 \\
-0.172 \\
-0.142
\end{array}\right]\left[\begin{array}{l}
\hat{\varepsilon}_{1 i t-1} \\
\hat{\varepsilon}_{2 i t-1} \\
\hat{\varepsilon}_{3 i t-1} \\
\hat{\varepsilon}_{4 i t-1}
\end{array}\right]+\left[\begin{array}{c}
\mu_{1 i t} \\
\mu_{2 i t} \\
\mu_{3 i t} \\
\mu_{4 i t}
\end{array}\right]
$$

From Table 4 and Eq. (19), the short-run and long-run elasticities have different meanings. Row (4a) reveals that energy consumption is not significantly correlated with real GDP, whereas capital formation and labor force have negative and statistically significant impact on real GDP in the short-run. With respect to Row (4b), only real GDP takes significantly effect on energy consumption, and the coefficient is 1.562 . But capital formation and labor force are not significantly correlated with energy consumption. It indicates the dynamics from real GDP to energy consumption is unidirectional. In terms of Row (4c), only real GDP has positive impact on capital formation. The effect of energy consumption and labor force are not significant. And for Row (4d), both energy consumption and capital formation take significantly negative effect on labor force, whereas estimator of real GDP on labor force is not significant. This shows that in China most of the increase of energy consumption and capital formation are not input into the social organizations (enterprises and government), but flow into the individuals and households. With respect to the long-run dynamics captured by the statistically significant error correction terms in Row (4a)-(4d), real GDP, energy consumption, capital formation and labor force each respond to short-run deviations from long-run equilibrium, since the estimation results of the ECM terms are all significant. Given the magnitude of the 
coefficients for the error correction terms, the speed of adjustment towards long-run equilibrium is rather slow. ${ }^{1}$

\subsubsection{Panel Granger Causality}

The augmented form of the Granger causality test involving the ECM is formulated in a multivariate q-th order panel VEC model as Eqs. (20) - (23).

$$
\begin{aligned}
& \Delta Y_{i t}=v_{1 j}+\sum_{k=1}^{q} \theta_{11 i k} \Delta Y_{i t-k}+\sum_{k=1}^{q} \theta_{12 i k} \Delta E_{i t-k}+\sum_{k=1}^{q} \theta_{13 i k} \Delta K_{i t-k}+\sum_{k=1}^{q} \theta_{14 i k} \Delta L_{i t-k}+\lambda_{1 i} E C M_{i t-1}+\mu_{1 i t} \\
& \Delta E_{i t}=v_{2 j}+\sum_{k=1}^{q} \theta_{21 i k} \Delta Y_{i t-k}+\sum_{k=1}^{q} \theta_{22 i k} \Delta E_{i t-k}+\sum_{k=1}^{q} \theta_{23 i k} \Delta K_{i t-k}+\sum_{k=1}^{q} \theta_{24 i k} \Delta L_{i t-k}+\lambda_{2 i} E C M_{i t-1}+\mu_{2 i t} \\
& \Delta K_{i t}=v_{3 j}+\sum_{k=1}^{q} \theta_{31 i k} \Delta Y_{i t-k}+\sum_{k=1}^{q} \theta_{32 i k} \Delta E_{i t-k}+\sum_{k=1}^{q} \theta_{33 i k} \Delta K_{i t-k}+\sum_{k=1}^{q} \theta_{34 i k} \Delta L_{i t-k}+\lambda_{3 i} E C M_{i t-1}+\mu_{3 i t} \\
& \Delta L_{i t}=v_{4 j}+\sum_{k=1}^{q} \theta_{4 l i k} \Delta Y_{i t-k}+\sum_{k=1}^{q} \theta_{42 i k} \Delta E_{i t-k}+\sum_{k=1}^{q} \theta_{43 i k} \Delta K_{i t-k}+\sum_{k=1}^{q} \theta_{44 i k} \Delta L_{i t-k}+\lambda_{4 i} E C M_{i t-1}+\mu_{4 i t} \\
& E C M_{i t}=\left[\begin{array}{l}
\hat{\varepsilon}_{1 i t-1} \\
\hat{\varepsilon}_{2 i t-1} \\
\hat{\varepsilon}_{3 i t-1} \\
\hat{\varepsilon}_{4 i t-1}
\end{array}\right]
\end{aligned}
$$

To infer the Granger causality relationship among variables, the F-test is applied to the joint hypothesis test. For example, if we test the Granger causality between variable $\mathrm{E}$ and $\mathrm{Y}$, the following hypothesis is tested:

Null hypothesis: $\mathrm{H}_{0}: \theta_{12 i k}=0(i=1,2, \ldots, n ; k=1,2, \ldots, q)$

Alternative hypothesis: $\mathrm{H}_{1}$ : There is at least one i or k that makes $\theta_{12 i k} \neq 0$

The statistic of the hypothesis test is

$$
\begin{aligned}
& \mathrm{S}=\frac{\mathrm{T}\left(R S S_{0}-R S S_{1}\right)}{R S S_{1}} \sim \chi^{2}(p) \\
& R S S_{1}=\sum_{t=1}^{T} \hat{\mu}_{1 i t}^{2} \\
& R S S_{0}=\sum_{t=1}^{T} \hat{\bar{\mu}}_{1 i t}^{2}
\end{aligned}
$$

where $\mathrm{RSS}_{1}$ is the summation of residuals' square in Eq. (20), and $\mathrm{RSS}_{0}$ is the summation of residuals' square of the following equation:

\footnotetext{
${ }^{1}$ The speed of adjustment is computed as the reciprocal of the absolute value of the coefficient on the respective error correction terms.
} 


$$
\Delta Y_{i t}=v_{1 j}+\sum_{k=1}^{q} \theta_{11 i k} \Delta Y_{i t-k}+\bar{\mu}_{1 i t}
$$

The Granger causality tests among other variables have the similar forms of joint hypotheses. Using the software Stata10, we derive $\chi^{2}$-statistic for every coefficient in the causality test, and the results are reported in Table 5. Panel Granger-causality tests reveal several interesting results from Table 5. On one hand, there is bidirectional causality between energy consumption and economic growth, which is consistent with the growth hypothesis in terms of the energy consumption-growth nexus. The growth hypothesis asserts that energy conservation policies which reduce energy consumption may have an adverse impact on economic growth. This is also the focus of the study. On the other hand, the unidirectional causality from capital formation to energy consumption indicates that energy consumption cannot affect economic growth through capital formation. Thus, excessive energy consumption may crowd out investment on manufacturing, or other sectors which is adverse for growth. This is also coincided with the natural resource curse hypothesis.

Table 5: Panel Granger causality tests

\begin{tabular}{|c|c|c|c|c|c|c|c|c|}
\hline \multirow[t]{2}{*}{$\begin{array}{c}\text { Dependent } \\
\text { variable }\end{array}$} & \multicolumn{8}{|c|}{ Sources of causation (independent variable) } \\
\hline & $\Delta \mathrm{Y}$ & Prob. & $\Delta \mathrm{E}$ & Prob. & $\Delta \mathrm{K}$ & Prob. & $\Delta \mathrm{L}$ & Prob. \\
\hline (5a) $\Delta Y$ & - & - & $175.65^{* * * *}$ & 0.000 & $212.19^{* * * *}$ & 0.000 & $158.85^{* * * \%}$ & 0.000 \\
\hline (5b) $\Delta \mathrm{E}$ & $202.32^{* * *}$ & 0.000 & - & - & $62.81^{* * * *}$ & 0.000 & $43.46^{* * * *}$ & 0.000 \\
\hline$(5 c) \Delta K$ & $567.65^{* * *}$ & 0.000 & 0.000 & 0.998 & - & - & $19.53^{* * *}$ & 0.000 \\
\hline (5d) $\Delta \mathrm{L}$ & $54.19^{* * *}$ & 0.000 & $95.14^{* * * *}$ & 0.000 & $8.23^{* *}$ & 0.016 & - & - \\
\hline
\end{tabular}

${ }^{* * * * *}$ denotes significance at the $1 \%$ level.

** denotes significance at the 5\% level.

${ }^{*}$ denotes significance at the $10 \%$ level.

\subsection{Panel VAR Model}

The structure of panel data in the paper is 30 provincial datasets over 1995 to 2010 . On one hand, China's economic structure has changed very quickly since 1978, so it is not appropriate for VAR model to estimate within a long-time. On the other hand, although the time dimension of the panel is not long, the large cross-section numbers can increase the volume of the samples, which could also derive consistent and valid estimators using the panel VAR model. As Mäki-Arvela (2003) argues, the unrestricted VAR methodology is ideally suited for an examination of interrelated time series variables and their dynamics in a labor market setting, where a particular focus is to explore the strengths of different adjustment mechanisms in response to economic shocks. According to the previous part, variables Y, E, K and L are all integrated of order one, and have the co-integration relationship. Thus, we can set the panel VAR model of lag one as:

$$
\left[\begin{array}{l}
\Delta Y_{i t} \\
\Delta E_{i t} \\
\Delta K_{i t} \\
\Delta L_{i t}
\end{array}\right]=\left[\begin{array}{l}
v_{1 j} \\
v_{2 j} \\
v_{3 j} \\
v_{4 j}
\end{array}\right]+\left[\begin{array}{l}
\theta_{11 i 1} \theta_{12 i 1} \theta_{13 i 1} \theta_{14 i 1} \\
\theta_{21 i 1} \theta_{22 i 1} \theta_{23 i 1} \theta_{24 i 1} \\
\theta_{31 i 1} \theta_{32 i 1} \theta_{33 i 1} \theta_{34 i 1} \\
\theta_{41 i 1} \theta_{42 i 1} \theta_{43 i 1} \theta_{44 i 1}
\end{array}\right]\left[\begin{array}{l}
\Delta Y_{i t-1} \\
\Delta E_{i t-1} \\
\Delta K_{i t-1} \\
\Delta L_{i t-1}
\end{array}\right]+\left[\begin{array}{l}
\theta_{11 i 2} \theta_{12 i 2} \theta_{13 i 2} \theta_{14 i 2} \\
\theta_{21 i 2} \theta_{22 i 2} \theta_{23 i 2} \theta_{24 i 2} \\
\theta_{31 i 2} \theta_{32 i 2} \theta_{33 i 2} \theta_{34 i 2} \\
\theta_{41 i 2} \theta_{42 i 2} \theta_{43 i 2} \theta_{44 i 2}
\end{array}\right]\left[\begin{array}{l}
\Delta Y_{i t-2} \\
\Delta E_{i t-2} \\
\Delta K_{i t-2} \\
\Delta L_{i t-2}
\end{array}\right]+\left[\begin{array}{l}
\mu_{1 i t} \\
\mu_{2 i t} \\
\mu_{3 i t} \\
\mu_{4 i t}
\end{array}\right]
$$

where $i$ represents different provinces; $t$ represents year; $v$ is the vector of provincial effect; $\theta$ are the coefficient matrices of variables in $\operatorname{lag}(1)$ and $\operatorname{lag}(2) ; \Delta$ is the first-difference operator; and $\mu$ is the serially uncorrelated error term.

The analysis of the panel VAR model can be divided into three parts. First, it estimates the panel VAR model by system GMM method to explain the relationship among variables; Second, it estimates the impulse response functions to draw the figures of dynamic shock responses, from which we can observe the dynamic changes of each variable under different shocks; Finally, based on the estimation of impulse response functions, it gives the results of variance decompositions for each variable, to evaluate the contributions of different stochastic shocks on the variables in the panel VAR system. 


\subsubsection{Estimation by System GMM}

To estimate the panel VAR model, firstly it is necessary to eliminate the fixed effect in Eq. (29). Making use of the Helmert-process of the program I.love (2006), Model (29) can be transformed through forward meandifferences. Then by system GMM method, we can obtain the valid estimation results of Model (29) shown as Table 6. It indicates that when variable $\mathrm{Y}$ is taken as dependent variable, the energy consumption takes negative and positive effect on real GDP for different lags. Coefficients of two lags are -0.3810 and 0.0239 respectively, which shows shocks of energy consumption firstly decrease real GDP to some degree, but the effect turn to be positive with the time backward. In China, because excessive energy consumption in a short time will crowd out great investment, and bring high pollution that has to be taxed, real GDP will be reduced to some degree. But from the long-run, proper energy consumption can promote economic growth. Moreover, when variable E is dependent variable, variables $\mathrm{Y}, \mathrm{K}, \mathrm{L}$ have positive impact on $\mathrm{E}$ in the first lags. Even in the second lags, Y still positively affects E. The coefficients of the two lags are 0.1612 and 0.1029 respectively, which means real GDP can always promote energy consumption in China.

Table 6: Estimation results of panel VAR model

\begin{tabular}{|c|c|c|c|c|c|c|c|c|}
\hline \multirow{3}{*}{$\begin{array}{l}\text { Independent } \\
\text { variable }\end{array}$} & \multicolumn{8}{|c|}{ Dependent variable } \\
\hline & h_Y & & h_E & & h_K & & h_L & \\
\hline & b_GMM & t_GMM & b_GMM & t_GMM & b_GMM & t_GMM & b_GMM & t_GMM \\
\hline L.h_Y & 1.5869 & 5.8458 & 0.1612 & 0.3748 & 1.3087 & 3.2050 & 0.1675 & 0.8332 \\
\hline L.h_E & -0.3810 & -3.7130 & 0.6848 & 4.6523 & -0.4422 & -3.0156 & -0.1155 & -1.3910 \\
\hline L.h_K & 0.0563 & 0.5845 & 0.2533 & 1.8419 & 1.2097 & 7.9687 & 0.0863 & 1.0352 \\
\hline L. h_L & 0.0209 & 0.3211 & 0.0053 & 0.0505 & 0.0391 & 0.4023 & 0.9689 & 17.3274 \\
\hline L2.h_Y & -0.3445 & -2.4092 & 0.1029 & 0.4981 & -0.6448 & -2.7343 & 0.0010 & 0.0090 \\
\hline L2.h_E & 0.0239 & 0.4870 & -0.1483 & -1.4530 & -0.0192 & -0.2978 & -0.0167 & -0.4638 \\
\hline L2.h_K & -0.0584 & -0.9580 & -0.2031 & -2.4200 & -0.3851 & -4.1423 & -0.0875 & -1.6972 \\
\hline L2.h_L & -0.0757 & -3.8314 & -0.1240 & -2.6561 & -0.1130 & -3.4019 & -0.0736 & -6.6960 \\
\hline
\end{tabular}

\subsubsection{Impulse Response Functions}

In order to assess the two-way effects among real GDP, energy consumption, capital formation and labor force, we compute impulse-response functions of the panel VAR model. The useful tool describes the reaction of one variable to innovations in another variable of the system, while holding all other shocks equal to zero. Figure 2 plots impulse-response functions together with 5 percent errors bands generated through Monte Carlo simulations with 500 repetitions.

From the first row of Figure 2, it shows the responses of real GDP to a one standard deviation shock in the remaining variables of the panel VAR (rescaled in terms of shocks of one standard deviation). As the figure shows, the shock of energy consumption changes is negative with most of the real GDP response being absorbed during the six years. With the lagged periods extend, the negative effect becomes bigger and bigger. The negative impact of energy consumption on growth indicates that it is impossible to improve economy by only depending on consuming resources. Excessive consumptions of energy can produce great waste and pollution with a short time, which have to afford higher costs. Some sectors can obtain energy easily, whereas other sectors' demand cannot be satisfied due to the uneven distributions in energy. Therefore, the energy shortage may happen in some sectors or regions in the short-run, which is adverse for economic growth. Furthermore, it will also crowd out investment on manufacturing and technology for large energy consumptions, which are considered as the fundamental factors determining the long-run growth of China. What is more, the shocks of capital formation and labor force on real GDP are not obvious in the short-run, but will become weakly negative for more lagged periods. This indicates that government investment of capital and labor in large scale is not actually reasonable, and will be harmful for economic orders from the long-run.

In addition, from the second row of the figure, the responses of energy consumption to a shock of real GDP are always positive during the six years. The responses will become larger and larger with more lagged periods, 
indicating the significant role of real GDP in promoting energy consumption. The shock of capital formation is also positively connected with energy consumption from the short-run, whereas the effect of labor force is stable from the short-run. We can conclude that in recent years, China's energy consumption is mainly driven by the investment demand instead of the household consumption.

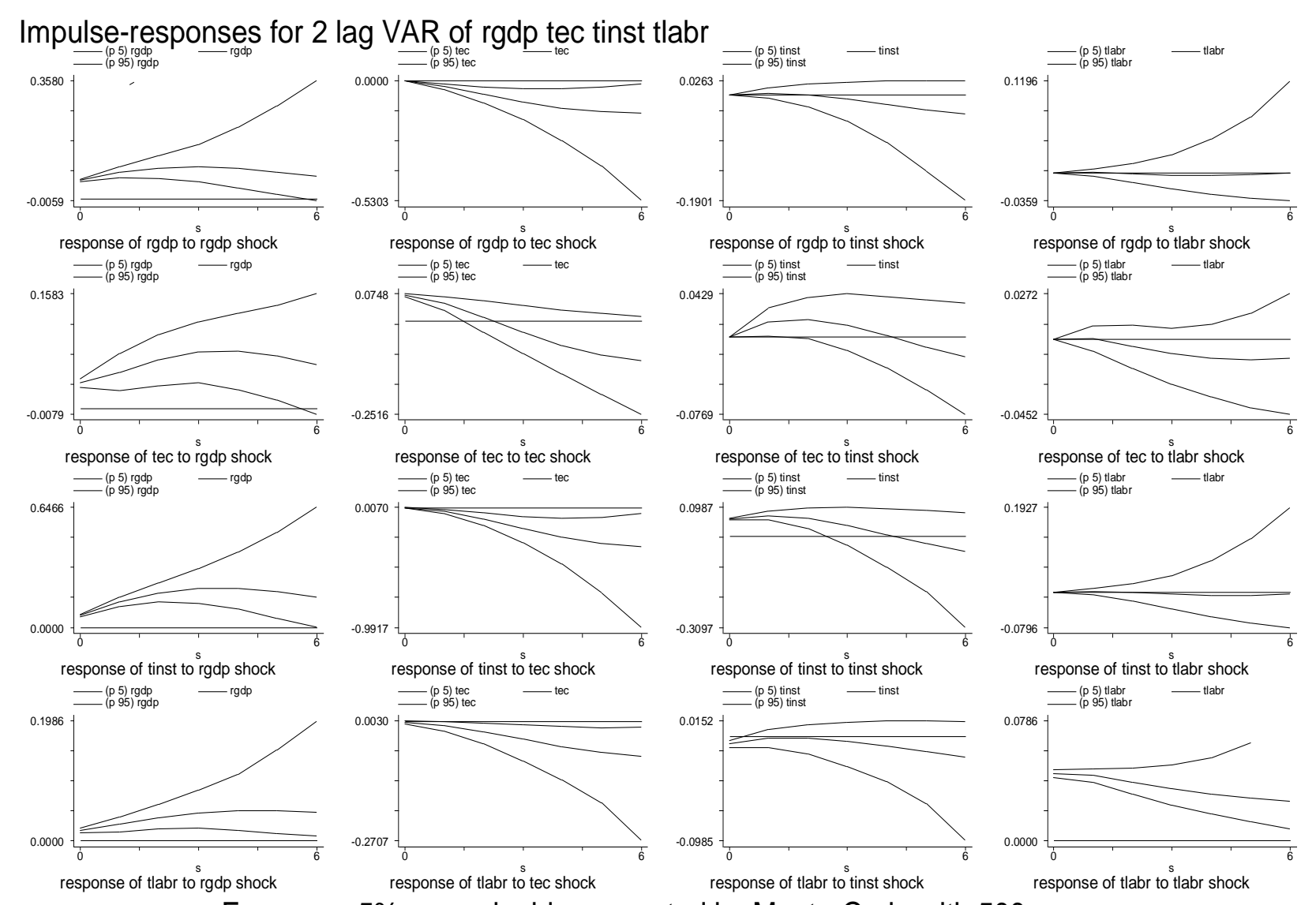

Errors are $5 \%$ on each side generated by Monte-Carlo with 500 reps

Figure 2: Variable impulse-responses of panel VAR model

Note: Confidence intervals are based on Monte Carlo simulations with 500 repetitions.

\subsubsection{Variance Decompositions}

Based on the impulse response function above, we can evaluate the relative importance of different structural shocks to endogenous variables by measuring the contributions of shocks on the variance changes of variables. Table 7 reports variance decompositions derived from the orthogonalized impulse-response coefficient matrices. The variance decompositions display the proportion of movements in the dependent variables that are due to their own shocks versus shocks to the other variables, which is done by determining how much of an s-step ahead forecast error variance of mean squared error (MSE) for each variable is explained by innovations to each explanatory variable (we report S until 30). We can conclude from Table 7 that a shock in the energy consumption has the biggest impact on real GDP in both short-run and long-run. The relative contributions during three periods are $33.38 \%, 29.76 \%$ and $28.31 \%$ respectively, a gradually decreasing trend. Furthermore, a shock in the capital formulation takes the biggest effect on energy consumption during the first two periods. However, real GDP replaces capital formulation and has the strongest impact on energy consumption over the third period. 
Table 7: Variance decomposition based on the impulse-responses

\begin{tabular}{cccccc}
\hline Variable & S & Y & E & K & L \\
\hline Y & 10 & 0.3042 & 0.6554 & 0.0388 & 0.0016 \\
E & 10 & 0.3338 & 0.6231 & 0.0370 & 0.0061 \\
K & 10 & 0.2945 & 0.6607 & 0.0437 & 0.0011 \\
L & 10 & 0.2430 & 0.5531 & 0.0402 & 0.1637 \\
\hline Y & 20 & 0.2656 & 0.6623 & 0.0487 & 0.0234 \\
E & 20 & 0.2976 & 0.6378 & 0.0488 & 0.01575 \\
K & 20 & 0.2565 & 0.6669 & 0.0532 & 0.0234 \\
L & 20 & 0.1974 & 0.5935 & 0.0575 & 0.1516 \\
Y & 30 & 0.2477 & 0.6646 & 0.0519 & 0.0357 \\
E & 30 & 0.2831 & 0.6437 & 0.0506 & 0.0225 \\
K & 30 & 0.2417 & 0.6684 & 0.0554 & 0.0345 \\
L & 30 & 0.1882 & 0.6100 & 0.0603 & 0.1415 \\
\hline
\end{tabular}

Note: The results are based on the orthogonalized impulse-responses. Percent of variation in the row variable is explained by column variable.

\section{CONCLUDING REMARKS}

This study adopts a panel data set for China's 30 provinces over the period 1995-2010 to investigate the causal and the dynamic relationship between energy consumption and economic growth, including two other factors of production: capital formation and labor force. To overcome the deficiency of the traditional time-series analysis, panel time-serious techniques are employed to derive more reasonable results. Before testing for causal and dynamic relationship among variables using panel method, panel unit root test and panel co-integration test should be performed in sequence. Firstly, the LLC test, Fisher-ADF test, Fisher-PP test, IPS test, and CIPS test all show that the variables are integrated of order one. Next, within dimension and between dimension approaches of Pedroni's heterogeneous panel tests indicate that there is a long-run co-integration relationship among variables real GDP, energy consumption, capital formation and labor force. Secondly, from the results of panel VEC model, the effect from economic growth to energy consumption is unidirectional, and the coefficient is 1.562. Real GDP, energy consumption, capital formation and labor force each respond to short-run deviations from long-run equilibrium with a slow adjustment speed. Furthermore, according to panel Granger causality test, there is bidirectional causality between real GDP and energy consumption, which is consistent with the growth hypothesis in terms of the energy consumption-growth nexus. The unidirectional causality from capital formation to energy consumption reveals that energy consumption cannot affect real GDP through capital formation, which may crowd out investment on manufacturing or other sectors. In addition, by estimating the panel VAR model and impulse response functions, it is indicated that the responses of real GDP to a shock of energy consumption are negative, whereas the shock of real GDP changes is positive with most of the energy consumption response being absorbed during the six years, showing excessive energy consumption of short-run could depress economic growth of long-run. Finally, by variance decompositions, derived from the orthogonalized impulse-response coefficient matrices, a shock in the energy consumption takes the biggest effect on real GDP in both short-run and long-run.

It becomes helpful for policy makers to recognize the new evidence from relationship between energy consumption and economic growth, because they give us many new thoughts into China's energy and growth policies. At least two measures should be implemented to overcome the present difficulties. On one hand, since energy consumption cannot have impact on economic growth through capital formation, policy makers should consider developing new energy and technology, and improving energy efficiency of usage, in order to attract more investment for the sustainable growth. On the other hand, while excessive consumptions of energy may be adverse for economy, it should be taken into account to reduce the unnecessary wastes and environmental costs, associated with dependence on production and consumption of non-renewable resources.

\section{ACKNOWLEDGEMENTS}

It is highly appreciated that Dr. Inessa Love of the World Bank provides us the program codes of Stata for the panel VAR model. 


\section{AUTHOR INFORMATION}

Shuai Chen, is a lecturer in Business School, University of Shanghai for Science and Technology, China, with a Ph.D. in economics from Kyushu University, Japan. E-mail: $\underline{\text { s.chen@ @usst.edu.cn }}$

\section{REFERENCES}

1. Apergis, N., D. Loomis, and J.E. Payne, 2010. Are Shocks to Natural Gas Consumption Temporary or Permanent? Evidence from a Panel of U.S. States. Energy Policy, 38, 4734-4736.

2. Apergis, N., and J.E. Payne, 2009. Energy Consumption and Economic Growth in Central America: Evidence from a Panel Cointegration and Error Correction Model. Energy Economics, 31, 211-216.

3. Apergis, N., and J.E. Payne, 2010. Energy Consumption and Growth in South America: Evidence from a Panel Error Correction Model. Energy Economics, 32, 1421-1426.

4. $\quad$ Apergis, N., and J.E. Payne, 2011. Renewable and Non-renewable Energy Consumption-Growth Nexus: Evidence from Panel Error Correction Model. Energy Economics, DOI: 10.1016/ j.eneco.2011.04.007.

5. Belke, A., F. Dobnik, and C. Dreger, 2011. Energy consumption and Economic Growth: New Insights into the Cointegration Relationship. Energy Economics, 33, 782-789.

6. Cerasa, A., 2008. CIPS Test for Unit Root in Panel Data: Further Monte Carlo Results. Economics Bulletin, Vol.3, No.16, 1-13.

7. Engle, R.F., and C.W.J. Granger, 1987. Co-integration and Error Correction: Representation, Estimation, and Testing. Econometrica, 55(2), 251-76.

8. Love, Inessa, and L. Zicchino, 2006. Financial Development and Dynamic Investment Behavior: Evidence from Panel VAR. The Quarterly Review of Economics and Finance, 46, 190-210.

9. Mahadevan, R., and J.A. Adjaye, 2007. Energy Consumption, Economic Growth and Prices: A Reassessment Using Panel VECM for Developed and Developing Countries. Energy Policy, 35, 24812490.

10. Mitze, T., 2012. A Panel VAR Approach for Internal Migration Modelling and Regional Labor Market Dynamics in Germany. Empirical Modelling in Regional Science, Lecture Notes in Economics and Mathematical Systems 657, DOI: 10.1007/978-3-642-22901-5_2.

11. Mäki-Arvela, P., 2003. Regional Evolutions in Finland: Panel Data Results of a VAR Approach to Labor Market Dynamics. Regional Studies, 37, 423-443.

12. Pedroni, P., 1999. Critical Values for Cointegration Tests in Heterogeneous Panels with Multiple Regressors. Oxford Bulletin of Economic and Statistics, 61, 653-678.

13. Pedroni, P., 2000. Fully Modified OLS for Heterogeneous Cointegrated Panels. Advances in Econometrics, 15, 93-130.

14. Pedroni, P., 2004. Panel Cointegration: Asymptotic and Finite Sample Properties of Pooled Time Series Tests with an Application to the PPP Hypothesis. Econometric Theory, 20, 597-625.

15. Pesaran, M.H., Y. Shin, and R.P. Smith, 1999. Pooled Mean Group Estimation of Dynamic Heterogeneous Panels. Journal of the American Statistical Association, 94(446), 621-634.

16. Pesaran, M.H., 2007. A Simple Panel Unit Root Test in the Presence of Cross-Section Dependence. Journal of Applied Econometrics, 22(2), 265-312.

17. Yang, S.Y., and D.H. Yu, 2011. The Causality between Energy Consumption and Economic Growth in China: Using Panel Method in a Multivariate Framework. Energy Procedia, 5, 808-812. 